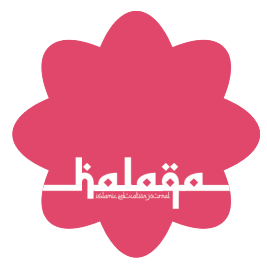

OPEN ACCESS ISSN 2503-5045 (online) ISSN 1412-9302 (print)

Edited by: Musfiqon Reviewed by: Imron Mustofa *Correspondence: Akhtim Wahyuni awahyuni@umsida.ac.id

Received: 5 Oktober 2020 Accepted: 12 Oktober 2020 Published: 25 Oktober 2020

Citation:

Wahyuni A (2020) Integration of Islamic Values in Science Education

'A Reconstruction Effort in

Education'.

Halaqa. 4:2.

doi: 10.21070/halaqa.v4i2.1000

\section{Integration of Islamic Values in Science Education 'A Reconstruction Effort in Education'}

\section{Integrasi Nilai-Nilai Islam Dalam Pendidikan Sains `Sebuah Upaya Rekonstruksi dalam dunia Pendidikan'}

\section{Akhtim Wahyuni* \\ Universitas Muhammadiyah Sidoarjo, Indonesia}

Islam and science are an inseparable unity. Islam as a religion is a source of knowledge and knowledge is a means to apply everything contained in religious teachings. In the Qur'an, there are around 750 verses related to science. This shows that Islam places great emphasis on the development of science. But what happens, these two things are pushed aside from each other, resulting in a dichotomy of knowledge that enters all aspects of life. The awareness to restore the position of Islam and science began to be rolled back by Muslim thinkers by integrating the two. In educational institutions, the integration of Islamic and science values is strengthened through an "integrated curriculum", which is "bringing together several scientific disciplines in a learning design to obtain better learning outcomes with the ability of students to connect one subject to another. Among the integration concepts offered are "shared, Webbed, and integrated." In addition to curriculum integration, components that need to be considered are improving the quality of human resources and educational infrastructure.

Keywords: Integration, Islamic Values, Science Education, Reconstruction

Islam sebagai agama merupakan sumber ilmu pengetahuan dan ilmu pengetahuan adalah sarana untuk mengaplikasikan segala sesuatu yang tertuang dalam ajaran agama. Di dalam al-Qur'an terdapat sekitar 750 ayat yang berkaitan degan ilmu pengetahuan. Hal ini menunjukkan bahwa Islam sangat menekankan pada pengembangan ilmu pengetahuan. Namun yang terjadi, dua hal ini saling dijauhkan, sehingga terjadi dikotomi ilmu yang masuk dalam semua aspek kehidupan. Kesadaran untuk mengembalikan kedudukan Islam dan sains mulai digulirkan kembali oleh para pemikir muslim dengan melakukan integrasi keduanya. Di lembaga pendidikan, integrasi nilai Islam dan sains dikuatkan melalui integrated curriculum" atau kurikulum terintegrasi, yakni "menyatukan beberapa disiplin keilmuan dalam sebuah disain pembelajaran untuk memperoleh hasil belajar yang lebih baik dengan kemampuan siswa mengkoneksikan antara satu subyek dengan lainnya. Di antara konsep integrasi yang ditawarkan adalah bentuk "shared, Webbed, dan integrated.

Kata Kunci: Integrasi, Nilai-nilai Islam, Pendidikan Sains, Rekonstruksi 


\section{PENDAHULUAN}

Hasil sebuah penelitian yang dilakukan oleh Muhammad Ijazul Haq dari Universitas Damaskus menemukan sebanyak 750 ayat dari sekitar 6.236 ayat al-Qur'an membicarakan mengenai ilmu pengetahuan. Dalam ayat-ayat tersebut Allah menghimbau umat Islam terutama kalangan intelektual untuk selalu berpikir kreatif dalam mengkaji fenomena alam serta menjadikan aktivitas ilmiah sebagai amaliah integral umat Islam. Himbauan seperti ini merupakan indikasi penting bahwa alQur'an komitmen dalam mengintegrasikan ilmu agama dan sains. Upaya integrasi nilai-nilai Islam terus dilakukan oleh para pemikir muslim. Abdullah (2015b) Awal munculnya ide integrasi ilmu dilatarbelakangi adanya dikotomi keilmuan antara ilmu umum dan ilmu agama, yang pada akhirnya melahirkan dikotomi sistem pendidikan. Contoh dikotomi dalam pendidikan di antaranya; Pendidikan Tinggi Umum dan Perpendidikan Tinggi Agama dengan induk yang berbeda, Lembaga pendidikan formal Dasar, Menengah, Atas, dan Madrasah, serta lain-lainnya. Lahirnya bidang ilmu yang membawa label Islam juga semakin berkembang, seperti: Ekonomi Islam, Psikologi Islam, Pendidikan Islam, Filsafat Islam, Sosiologi Islam, dan lain-lain. Padahal dalam Islam tidak mengenal adanya dikotomi ilmu, sebab sumber ilmu dalam Islam hanya satu yakni Al-Quran. Oleh karena itu posisi ilmu pengetahuan dalam Islam harus direkontruksi kembali dengan paradigma baru, bahwa Islam mengintegrasikan seluruh sistem ilmu pengetahuan dalam satu kerangka dengan pendekatan wahyu (al-Qur'an), filsafat, dan pendekatan empirik baik dalam pembahasan, substansi ilmu maupun fungsi dan tujuan ilmu pengetahuan itu sendiri.

Dalam pendidikan, salah satu bentuk integrasi ilmu adalah integrasi kurikulumnya. Format integrasi kurikulum sains dan agama bentuknya beragam. Ada yang berbentuk Islamisasi ilmu yang dilakukan dengan cara keilmuan Islam seperti ayat-ayat kauniyah berupaya mengintervensi keilmuan umum, sehingga keilmuan tersebut menjadi Islami atau lebih dikenal dengan Islamisasi ilmu. Bentuk lainnya, integrasi dengan mengacu pada model-model yang dikembangkan oleh para ahli kurikulum dengan memasukkan dua disiplin ilmu pada satu desain pembelajaran, dan lainnya. Selain kurikulum, Sumber Daya Manusia (SDM) dan sarana prasarana menjadi instrumen penting untuk diimpementasikannya integrasi nilai-nilai Islam dalam pendidikan sains. Sebagus apapun kurikulum yang sudah didesain tapi jika tidak dibarengi dengan mutu SDM dan sarana prasarana yang sesuai dengan kebutuhan, maka integrasi nilai-nilai Islam dalam pendidikan sains akan susah untuk diwujudkan.

\section{METODE}

Desain penelitian ini adalah Literature Review atau tinjauan pustaka. Studi literature review adalah cara yang dipakai untuk megumpulkan data atau sumber yang berhubungan pada sebuah topik tertentu yang bisa didapat dari berbagai sumber seperti jurnal, buku, internet, dan pustaka lain. Hamzah (2019)

\section{PEMBAHASAN}

\section{Konsep Integrasi Kurikulum Agama dan Sains}

Pendidikan merupakan salah satu aspek penting dalam pengembangan manusia dan menjadi institusi sosial yang paling berpengaruh di masyarakat. Secara umum, pendidikan sebagai media transfer nilai, kepercayaan, norma, juga pemahaman Ishaq (2009). Islam memandang bahwa pendidikan sebagai bentuk ibadah dimana orang Islam berbagi tentang pengetahuan yang mengacu pada al-Quran dan alSunnah. Hassan (2003) menjelaskan pendidikan dalam perspektif Islam yaitu sebagai proses panjang dalam menyiapkan individu untuk mengaktualisasikan perannya sebagai Khalifah Allah di bumi dan harus berkontribusi secara penuh dalam pembentukan dan pengembangan masyarakatnya agar mencapai kesejahteraan dunia dan akhirat.

Pengembangan kurikulum merupakan istilah yang komprehensif, di dalamnya mencakup perencanaan, penerapan dan evaluasi. Prinsip-prinsip yang akan digunakan dalam kegiatan pengembangan kurikulum pada dasarnya merupakan kaidah-kaidah atau hukum yang akan menjiwai suatu kurikulum. Dalam pengembangan kurikulum, dapat menggunakan prinsip-prinsip yang telah berkembang dalam kehidupan sehari-hari atau justru menciptakan sendiri prinsip-prinsip baru. Oleh karena itu, dalam implementasi kurikulum di suatu lembaga pendidikan sangat mungkin terjadi penggunaan prinsip-prinsip yang berbeda dengan kurikulum yang digunakan di lembaga pendidikan lainnya, sehingga akan ditemukan banyak sekali prinsip-prinsip yang digunakan dalam suatu pengembangan kurikulum. Konsep Integrasi kurikulum merupakan sebuah tawaran epistologis sekaligus metodologis untuk membawa peserta didik kepada keseimbangan dan kesadaran akan eksistensi dirinya sebagai hamba Allah dan khalifah Allah di satu sisi dan perkembangan IPTEK di sisi lain.

\section{Model Integrasi Kurikulum Agama dan Sains}

Pemikir muslim Amin Abdullah memunculkan gagasan tentang penyatuan ilmu ini dengan istilah "Integratif-interkonektif. Salah satu bentuk implementasinya adalah adanya kurikulum yang dibekali dengan spiritualitas dan moral keagamaan yang kritis dan terarah dalam format "integrated curriculum" Idi (2007) . Dengan rekonstruksi ilmu pengetahuan ini dalam Islam tidak lagi ditemui dikotomi antara ilmu pengetahuan umum dan Islam, namun keduanya saling berhubungan secara fungsional (functional correlation). Sebagaimana masa kejayaan Islam yang terkenal dengan "The Golden Age of Science in Islam" pada kurun waktu antara tahun 650-1250 M, dimana ilmu pengetahuan terintegrasi secara sistematis Jafar (2015) 
Konsep ilmu-ilmu ke-Islam-an, oleh beberapa pemikir Muslim juga biasa disebut dengan 'sains Islam'. Mengapa sains Islam, Butt (1996) mengatakan bahwa jika sains memang sarat nilai dengan komponen penting yang bersifat subjektif (juga objektif), maka tentunya ia bisa dikembangkan melalui selera dan penekanan kultural yang khas. Artinya, di dalam sebuah masyarakat Islam, nilai yang membentuk upaya sains dan teknologi haruslah nilai Islami, yang dalam istilah singkatnya disebut sebagai konsep sains Islam.

Untuk memberikan pemahaman yang memadai tentang konsep integrasi keilmuan, yang pertama-tama perlu dilakukan adalah memahami konteks munculnya ide integrasi keilmuan tersebut. Bahwa selama ini di kalangan umat Islam terjadi suatu pandangan dan sikap yang membedakan antara ilmu-ilmu ke-Islam-an di satu sisi, dengan ilmu-ilmu umum di sisi lain. Ada perlakukan diskriminatif terhadap dua jenis ilmu tersebut. Umat Islam seolah terbelah antara mereka yang berpandangan positif terhadap ilmu-ilmu ke-Islaman sambil memandang negatif yang lainnya, dan mereka yang berpandangan positif terhadap disiplin ilmu-ilmu umum sembari memandang negatif terhadap ilmu-ilmu ke-Islam-an.

Dari konteks yang melatari munculnya ide integrasi keilmuan tersebut, maka integrasi keilmuan pertama-tama dapat dipahami sebagai upaya membangun suatu pandangan dan sikap yang positif terhadap kedua jenis ilmu yang sekarang berkembang di dunia Islam. Ali sebagaimana dikutip Butt (1996) kemudian memberikan pengertian integrasi keilmuan Integration of sciences means the recognition that all true knowledge is from Allah all sciences should be treated with equal respect whether it is scientific or revealed. Konsepsi integrasi keilmuan berangkat dari premis bahwa semua pengetahuan yang benar berasal dari Allah (all true knowledge is from Allah). Dalam pengertian yang lain, Amir Ali juga menggunakan istilah all correct theories are from Allah and false theories are from men themselves or inspired by Satan. Dengan pengertian yang hampir sama Hassan (2003) menggunakan istilah "knowledge is the light that comes from Allah “

Konsep integrasi keilmuan juga berangkat dari doktrin keEsaan Allah (tauhid), sebagaimana dikemukakan oleh and (1970), the arts and sciences in Islam are based on the idea of unity, which is the heart of the Muslim revelation. Doktrin keesaan Tuhan, atau iman dalam pandangan Isma'il Razi al Faruqi, bukanlah semata-mata suatu kategori etika. Ia adalah suatu kategori kognitif yang berhubungan dengan pengetahuan, dengan kebenaran proposisi-proposisinya.

Integrasi sains dengan agama harus dirancang dengan baik, sejak perencanaan dan perancangan kurikulum, disain pembelajaran, praktik dan pelatihan dan bahkan evaluasi pencapaian hasil belajar. Sejauh ini, teori integrasi antar subject matter dalam desain kurikulum yang sudah dikenal di kalangan komunitas ilmu pendidikan adalah "integrated curriculum" atau kurikulum terintegrasi, yakni "menyatukan beberapa disiplin keilmuan dalam sebuah disain pembelajaran untuk memperoleh hasil belajar yang lebih baik dengan kemampuan siswa mengkoneksikan antara satu subyek dengan lainnya" (Perry,
2010), agar bisa difahami secara holistik, realistik dan bisa dilaksanakan secara aksiologis. Pengembangan media pembelajaran digital yang mengintegrasikan pada nilai-nilai Islam dan sains terbukti efektif mampu meningkatkan nilai-nilai karakter religious siswa Fahyuni et al. (2020).

Pengembangan model kurikulum terintegrasi sudah dilakukan oleh mereka yang terus mengembangkan penelitian tentang curriculum development, dan tidak hanya menyentuh aspek penyusunan subject matter, tapi justru lebih banyak memanfaatkan wilayah syllabus, pelaksanaan pembelajaran, serta pengukuran hasil-hasil belajar. Salah satunya adalah Robin Fogarty, Doktor dalam bidang curriculum and human resource development dari Loyola University of Chicago, yang kemudian aktif dalam bidang pendidikan, penelitian dan konsultansi di berbagai negara di dunia. Salah satu temuannya yang sangat monumental dan banyak dibaca akademisi adalah "ten ways to integrate curriculum". Di antara konsep integrasi yang ditawarkannya adalah bentuk "shared, Webbed, dan integrated" Alhamuddin (2012).

1. Model shared ini adalah kurikulum seperti teropong binocular, yakni memasukkan dua disiplin ilmu pada satu disain pembelajaran (Fogarty,2009). Dalam konteks integrasi sains dan agama adalah memasukkan unsur sains pada mata kuliah keagamaan murni, yakni aqidah, ibadah dan akhlak, dan atau juga bisa memasukkan unsur keagamaan pada mata kuliah profesi keilmuan. Penjelasan aqidah, akan sangat bisa diterima logika, jika diperkuat pernjelasan yang saintifik. Oleh sebab itu, perlu pelibatan sains dalam menjelaskan aqidah pada para mahasiswa. Demikian pula dalam pembahasan fiqh, banyak hal yang memerlukan penjelasan saintifik, agar pelaksanaan agama menjadi tidak bertentangan dengan sains, dan bahkan sains akan sangat memperkuat doktrin keagamaan

2. Model web ini bisa disebut juga sebagai kurikulum yang mampu menangkap semua disiplin dalam satu disain. Untuk konteks integrasi sain dan agama, model ini adalah model teleskop yang dapat menangkap semua pokok bahasan dari berbagai disiplin ilmu untuk mencapai satu fokus tujuan (Fogarty:2009) Nicholls and Nicholls (1982) . juga dikembangkan bukan dalam konteks sebaran mata kuliah/pelajaran, tapi justru pada tema-tema perkuliahan/pelajaran. Mata kuliah/pelajaran tertentu biasanya mata kuliah kompetensi utama, yang akan sangat menentukan profesionalisme mereka, dan pasti memerlukan muatan nilai keagamaan baik pada dimensi epistimologi maupun aksiologinya, maka pada mata kuliah tersebut, masuk tema-tema keagamaan, baik penjelasan doktrin agama tentang teori yang sedang dipelajarinya, maupun nilai agama dalam aksiologi ilmu untuk kepentingan kemanusiaan dan peradaban dunia. Dengan demikian, model webbed ini memerlukan team teaching yang antara dosen sains dan dosen agama memiliki pengetahuan yang lintas batas, karena mereka boleh masuk secara independen dan menjelaskan tema-temanya masing-masing. 
Kedua model desain silabus ini menghendaki pendekatan perlakuan mengajar yang berbeda. Pendekatan Shared model menggunakan team teaching, yakni dua orang dosen masuk kelas bersamaan, dalam pokok bahasan yang sangat signifikan untuk diintegrasikan. Oleh sebab itu, sebelum perkuliahan dimulai, team dosen ini melakukan pemetaan konsep, tentang pokok-pokok bahasan yang akan diajar dengan team, dan pokok bahasan yang diajar secara independen oleh masingmasing dosen. Dan juga dipetakan konsepnya, apakah integrasi dalam epistimologi, atau aturan-aturan normatif pada wilayah aksiologi. Sementara untuk model webb, diperlukan team dosen, tapi tidak menuntut masuk bersamaan. Mereka berbagi tema-tema. Pada model ini, akan terjumpai irisanirisan bahasan dalam tema masing-masing. Oleh sebab itu, dosen agama harus memiliki pengetahuan tentang sains yang diajarkannya, dan dosen sains juga harus memiliki pengetahuan tentang ilmu agama yang terintegrasi, sehingga bisa menjelaskan integrasinya dengan baik, walaupun penjelasan detail oleh masing-masing ahlinya. Abdullah (2015b)

Model ketiga yang juga relevan untuk integrasi sains dan agama adalah integrated model, yakni mengintegrasikan beberapa disiplin keilmuan untuk membentuk satu konsep, skill dan sikap. Model ini mengimplikasikan penyiapan disain pembelajaran yang dianalisis dengan seksama secara team oleh team dosen yang akan mengajar, pada area mana agama secara epistimologis akan masuk, dan pada area mana agama secara normatif akan masuk, dan pada area mana agama secara aksiologis akan masuk. Pada saat memasuki area studi keagamaan, maka dosen agama memberikan penjelasan pada para mahasiswa, dan akan lebih baik bila dilakukan bersama dengan dosen sains, agar para mahasiswa merasa yakin dengan pengetahuan barunya itu, karena didampingi oleh semua dosennya, dan mereka bisa mempertimbangkan untuk menjadikannya sebagai nilai dalam diri mereka. and (2013)

\section{Penguatan Sumber Daya Manusia}

Dalam konteks integrasi nilai-nilai Islam pada pendidikan sains ini, Sumber Daya Manusia menjadi salah satu pilar penting dalam menerjemahkan kurikulum yang sudah dirancang untuk disajikan kepada subjek pendidikan. Sebaik apapun konten atau kurikulum yang disajikan, bila tidak dapat diterapkan oleh pendidik yang berkualitas akan tidak bermakna. Pengembangan SDM dalam rangka meningkatkan kualitas pendidikan harus menjadi prioritas. Hal ini mengingat bahwa dalam suatu organisasi atau lembaga pendidikan, dapat maju dan berkembang dengan dukungan dari sumber daya manusia. Oleh karena itu setiap lembaga pendidikan atau organisasi yang ingin berkembang, maka harus memperhatikan sumber daya manusia dan mengelolanya dengan baik, agar tercipta pendidikan yang bermutu. Hamalik (2006)

Dalam pengembangan SDM, pimpinan lembaga pendidikan merupakan kunci keberhasilan untuk mencapai kualitas pendidikan. Ia dituntut untuk senantiasa berusaha mem- bina dan mengembangkan SDM sesuai dengan kebutuhan. Pentingnya pengembangan sumber daya manusia dalam meningkatkan mutu pendidikan, didasari oleh:

1. Sumber daya manusia merupakan faktor sentral dalam pendidikan,mengingat perannya yang sangat penting dalam meningkatkan kualitas pendidikan.

2. Merujuk pendapat dari Mulayasa yang mengemukakan bahwa selain merupakan modal yang paling vital, sumber daya manusia (SDM) juga merupakan pelanggan internal yang menentukan kualitas akhir suatu produk dan organisasi.

3. Mengingat pentingnya berbagai sektor pembangunan, maka SDM perlu ditata atau manaj sedemikian rupa agar diperoleh hasil yang optimal.

4. Dengan pemanfaatan sumber daya manusia oleh pimpinan dalam suatu lembaga secara efektif dan efisien, akan mengoptimalkan pencapaian tujuan lembaga dan pemanfaatan SDM dimulai dari melakukan perencanaan yang tepat, pengorganisasian yang mantap, penyusunan staf yang tepat dan profesional, pengarahan dan pengawasan yang terkendali dengan baik akan menjamin berfungsinya proses manajerial.

5. Pendidik merupakan sumber daya insani yang sangat penting peranannya dalam mendidik dan mengajar karena berhasilnya kegiatan belajar mengajar bergantung pada kemampuan pendidik dalam menyusun atau merancang belajar mengajar.

6. Manajemen sumber daya manusia termasuk salah satu bagian dari manajemen lembaga secara keseluruhan, dan manajemen sumber daya manusia menduduki tempat yang sangat penting. Dikatakan demikian karena pendidik adalah faktor sentral dalam pendidikan.

Maka SDM untuk implementasi integrasi nilai-nilai Islam dalam pendidikan sains perlu dilatih dan ditingkatkan kualitasnya secara khusus agar mampu merancang kurikulum yang ideal, mengimplementasikan, dan mengembangkan keilmuan secara terus menerus sesuai kebutuhan dan perkembangan zaman.

\section{Pengembangan Sarana dan Prasarana}

Salah satu aspek yang perlu mendapat perhatian utama oleh setiap pengelola pendidikan adalah fasilitas pendidikan. Sarana pendidikan umumnya mencakup semua fasilitas yang secara langsung dipergunakan dan menunjang proses pendidikan, seperti: Gedung, ruangan belajar atau kelas, laboratorium, alat-alat atau media pendidikan, meja, kursi, dan sebagainya. Sedangkan yang dimaksud dengan prasarana adalah yang secara tidak langsung menunjang jalannya proses pendidikan, seperti: halaman, kebun atau taman lembaga, maupun jalan menuju ke lembaga. Mulyasa (2014)

Setiap bidang kajian memiliki karakter yang berbeda dengan bidang lainnya. Dengan demikian, masing-masing bidang 
juga memerlukan sarana pembelajaran yang berbeda pula. Dalam menyelenggarakan pembelajaran pendidik pastinya memerlukan sarana yang dapat mendukung kinerjanya sehingga pembelajaran dapat berlangsung dengan menarik. Dengan dukungan sarana pembelajaran yang memadai, pendidik tidak hanya menyampaikan materi secara lisan, tetapi juga dengan tulis dan peragaan sesuai dengan sarana prasaranayang telah disiapkan pendidik. and (2005)

Pendidik membutuhkan sarana pembelajaran dalam menunjang kegiatan pembelajaran. Selain kemampuan pendidik dalam menyelenggarakan kegiatan pembelajaran, dukungan dari sarana pembelajaran sangat penting dalam membantu pendidik. Semakin lengkap dan memadai sarana pembelajaran yang dimiliki sebuah lembaga akan memudahkan pendidik dalam melaksanakan tugasnya sebagai tenaga pendidikan. Begitu pula dengan suasana selama kegiatan pembelajaran. Sarana pembelajaran harus dikembangkan agar dapat menunjang proses belajar mengajar. Yamin menyebutkan beberapa hal yang perlu dikembangkan dalam menunjang proses belajar mengajar: 1) perpustakaan, 2) sarana penunjang kegiatan kurikulum, dan 3) prasarana dan sarana kegiatan ekstrakurikuler dan mulok. Abdullah (2015a)

Mengingat pentingnya sarana prasarana dalam kegiatan pembelajaran, maka peserta didik, pendidik dan lembaga akan terkait secara langsung. Peserta didik akan lebih terbantu dengan dukungan sarana prasarana pembelajaran. Tidak semua peserta didik mempunyai tingkat kecerdasan yang bagus sehingga penggunaan sarana prasarana pembelajaran akan membantu peserta didik, khususnya yang memiliki kelemahan dalam mengikuti kegiatan pembelajaran. Bagi pendidik akan terbantu dengan dukungan fasilitas sarana prasarana. Kegiatan pembelajaran juga akan lebih variatif, menarik dan bermakna. Sedangkan lembaga berkewajiban sebagai pihak yang paling bertanggung jawab terhadap pengelolaan seluruh kegiatan yang diselenggarakan. Selain menyediakan, lembaga juga menjaga dan memelihara sarana prasarana yang telah dimiliki. Susanto (2015)

\section{REFERENCES}

Abdullah, M. A. (2015a). Islamic Studies di Pendidikan tinggi (Yogyakarta: Pustaka Pelajar).

Abdullah, M. A. (2015b). Religion, Science, and Culture: An Integrated, Interconnected Paradigm of Science. Journal of Islamic Studies 52, 175-203. doi: https://doi.org/10.14421/ajis.2014.521.175-203.

Alhamuddin (2012). Pengembangan Kurikulum Jurusan Pendidikan Agama Islam (PAI) dalam Upaya Mencetak Guru Agama Profesional (Sebuah Analisis Deskriptif dalam Konteks UUGD). Jurnal Al-Furqan: Jurnal Studi Pendidikan Islam 1, 29-36.

and, M. A. A. (2013). Integrasi Interkoneksi Keilmuan (Yogyakarta: SUKA Press).

and, N. S. S. (2005). Pengembangan Kurikulum: Teori dan Praktik (Bandung: Remaja Rosdakarya), 1-220.

and, S. H. N. (1970). Science and Civilization in Islam (Cambridge, United Kingdom: Islamic Texts Society).

Butt, N. (1996). Sains dan Masyarakat Islam (Jakarata: Pustaka Hidayah).

Fahyuni, E. F., Wasis, W., Bandono, A., and Arifin, M. B. U. B. (2020). Inte-
Dalam menunjang penerapan integrasi nilai-nilai Islam dalam pendidikan sains ini dibutuhkan sarana dan prasarana yang sesuai dengan kebutuhan. Umumnya, kurikulum yang didesain tidak klop dengan sarana prasarana yang ada. Hal ini disebabkan karena proses bekerja yang tidak nyambung antar unit atau bagian. Masing-masing dihandle oleh yang membidangi bidang kerja. Jadi umumnya disesuaikan dengan selera penanggung jawab bidangnya. Padahal kebutuhan dari komponen-komponen yang ada ini sejatinya untuk menuju visi yang sama. Pada akhirnya, proses yang dilaksanakan tidak bisa maksimal dan mencapai goal yang ditetapkan. Maka harus ada penyamaan visi dalam semua proses integrasi nilai-nilai agama dalam pendidikan sains ini. Mashudi (2002) Contoh paling sederhana kebutuhan sarana prasarana dalam lembaga pendidikan terkait penguatan nilai-nilai Islam dalam pendidikan adalah tersedianya laboratorium-laboratorium sesuai bidang kajian. Laboratorium tersebut menjadi center for research untuk pengembangan keilmuan Islam.

\section{KESIMPULAN}

Konsepsi integrasi agama dan sains berdampak pada kajian keilmuan di Indonesia termasuk dunia pendidikan perlu disikapi dengan cerdas karena hal ini menjadi kebutuhan yang urgen. Kajian-kajian wawasan memang perlu untuk mengasah pemikiran ini, namun yang terpenting adalah melakukan kegiatan kongkrit untuk mengeksperimenkan dan mempraktekkan teori-teori yang sudah ada dalam nash al-Qur'an dan alSunnah. Center for Islamic research perlu dibentuk di lembagalembaga pendidikan untuk melakukan kajian dan melahirkan teori-teori yang bisa menjadi referensi dalam pengembangan keilmuan Islam dengan didukung SDM dan sarana prasarana yang memadahi. Teori-teori yang sudah dilahirkan dari dunia Barat dalam bidang pendidikan dapat pula menjadi rujukan dan pembanding terhadap pengembangan keilmuan, karena sejatinya dikotomi ilmu umum dan agama itu tidak ada. Ilmu itu satu, bersumber dari Allah Swt.

grating Islamic Values and Science for Millennial Students' Learning on Using Seamless Mobile Media. Jurnal Pendidikan IPA Indonesia 9, 231-240. doi: 10.15294/jpii.v9i2.23209.

Hamalik, O. (2006). Manajemen Pengembangan Kurikulum Sekolah (Bandung: PT. Remaja Rosda Karya).

Hamzah, A. (2019). Metode Penelitian dan Pengembangan (Jakarta: Literasi Nusantara).

Hassan, U. (2003). The Concept of Ilm and Knowledge in Islam (The Association of Muslim Scientists and Engineers).

Idi, A. (2007). Pengembangan Kurikulum: Teori dan Praktek (Yogyakarta: Ar Ruz Media).

Ishaq, F. (2009). Islamization of the Dicipline of Education. The American Journal of Islam Social Science 6.

Ja'far, H. (2015). Indonesian Islamic Education: Towards Science Development. Walisongo: Jurnal Penelitian Sosial Keagamaan 23, 331-375.

Mashudi (2002). Reintegrasi Epistimologi Pengembangan Keilmuan di UIN Sunan Kalijaga Yogyakarta. http://digilib.uin-suka.ac.id/id/eprint/1339.

Mulyasa, E. (2014). Manajamen Berbasis Sekolah (Bandung: PT. Remaja Ros- 
dakarya).

Nicholls, A. and Nicholls, S. H. (1982). Developing a Curriculum: A Practical Guide (Routledge Library Editions: Curriculum). In Developing a Curriculum: A Practical Guide New Edition (London: George Allen \& Unwin).

Susanto, P. (2015). Perbandingan Pendidikan Islam di Asia Tenggara. Journal of Islamic Education 4, 71-74. doi: https://doi.org/10.14421/jpi.2015.41.71-93.

Conflict of Interest Statement: The author declare that the research was conducted in the absence of any commercial or financial relationships that could be construed as a potential conflict of interest.

Copyright $\odot 2020$ Wahyuni. This is an open-access article distributed under the terms of the Creative Commons Attribution License (CC BY). The use, distribution or reproduction in other forums is permitted, provided the original author(s) and the copyright owner(s) are credited and that the original publication in this journal is cited, in accordance with accepted academic practice. No use, distribution or reproduction is permitted which does not comply with these terms. 